Territorios 33 / Bogotá, 2015, pp. 63-81

ISSN: 0123-8418

ISSNe: 2215-7484

Procesos de ocupación del territorio, historia urbana y patrimonio II

\title{
Una reflexión sobre las periferias metropolitanas de la ciudad de Cali, tomando como referente la literatura y el patrimonio construido*
}

A Reflection on the Metropolitan Peripheries of the City of Cali Taking as Reference Literature and Built Heritage

Uma reflexão sobre as periferias metropolitanas da cidade de Cali tomando como referente a literatura e o patrimônio construido

Pedro Martín Martínez Toro**

Recibido: 15 de septiembre de 2014

Aprobado: 24 de abril de 2015

Doi: dx.doi.org/10.12804/territ33.2015.03

Para citar este artículo:

Martínez, T. P. M. (2015). Una reflexión sobre las periferias metropolitanas de la ciudad de Cali, tomando como referente la literatura y el patrimonio construido. Territorios, 33, 63-81. doi: dx.doi.org/10.12804/territ33.2015.03

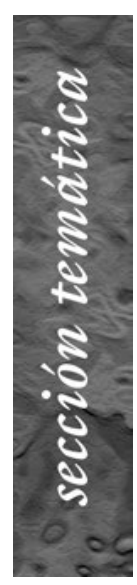

* Este artículo es producto del proceso de investigación del autor en la formulación de su proyecto de investigación doctoral, dirigido por el doctor Luis Mauricio Cuervo, en el marco del Doctorado en Estudios Territoriales de la Universidad de Caldas, Colombia. El titulo del proyecto de investigación doctoral en el cual este articulo se inscribe es "Relaciones entre la globalización y el mercado inmobiliario en el proceso de metropolización de la ciudad de Cali entre 1980 y 2012".

** Arquitecto (Universidad del Valle, Cali), Máster en Politica territorial y urbanistica (Universidad Carlos III de Madrid, España), Estudios doctorales en geografía urbana (Universidad Autónoma de $\mathrm{Ma}$ - $\Rightarrow$ 
Palabras clave

Periurbanización, patrimonio arquitectónico,

Cañasgordas, Cali, metropolización.

Keywords

Periurbanization, architectural heritage,

Cañasgordas, Cali, metropolization.

Palavras-chave

Periurbanização, património arquitetônico,

Cañasgordas, Cali, metropolização.

\section{territarias 33}

\section{RESUMEN}

En los cambios urbanos de la ciudad de Cali, que van desde el pequeño asentamiento concentrado y de extensión de unas pocas manzanas en la época de la colonia española, hasta los recientes impactos de la globalización sobre la metropolización de la ciudad de Cali, desplegándose al sur del departamento del Valle y al norte del departamento del Cauca, durante el periodo que se desarrolla desde la década de 1980 hasta estos días, pueden identificarse las dinámicas expansivas de carácter difuso, disperso y fragmentado que afectan las periferias urbanas, convirtiéndolas en los territorios que expresan con mayor evidencia la rapidez y características de dicha transformación.

Este artículo tiene como base las posibilidades con las que cuenta la literatura del género de la crónica o de la novela costumbrista, regionalista e histórica como insumo complementario para el estudio de la historia de la ciudad. En un primer apartado, se identifican las periferias metropolitanas en su carácter paisajístico y dinámico, como muestra del cambio urbano, lo que se complementa con la pertinencia de los estudios de la geografía histórica. Y, en un segundo apartado, se utiliza el libro El Alférez Real de José Eustaquio Palacios, que narra los paisajes y trayectos entre la hacienda Cañasgordas y la ciudad de Cali en 1789, describiendo el asentamiento urbano y la extensa distancia, para entonces (diez kilómetros), de áreas rurales que las separaba y que era recorrida a caballo.

\section{ABSTRACT}

In the urban changes in the city of Cali, ranging from the small concentrated township and extension of a few blocks at the time of the Spanish colony until the recent impacts of globalization on metropolization of Cali City, unfurling the southern department of Valle north of Cauca, during the period that is developed from the 1980s to this day, can identify the expansive dynamics of diffuse, scattered and fragmented nature affecting urban neighborhoods, making them the territories more evidence expressing the speed and features of this transformation.

This article is based on the possibilities that literature genre has chronic or folkloric, regionalist and historical novel as a complementary input for the study of the history of the city. In the first section, metropolitan peripheries are identified in its landscape and dynamic, as a sign of urban change, which complements the relevance of studies of historical geography. And, in a second section, the book El Alférez Real by José Eustaquio Palacios, who narrates the landscapes and routes between the ranch Cañasgordas and the city of Cali in 1789, describing the urban settlement and the vast distance is used, then (ten kilometers) of rural areas that separated and it was crossed on horseback.

\section{RESUMO}

Nas mudanças urbanas da cidade de Cali, que vão desde o pequeno assentamento concentrado e de extensão de uns poucos quarteirões na época da colônia espanhola até os recentes impactos da globalização sobre a metropolização da cidade de Cali dispersando-se ao sul do Departamento do Valle e ao norte do Departamento do Cauca durante o período que se desenvolve desde a década de 1980 até nossos dias, em dinâmicas expansivas de carácter difuso, disperso e fragmentado que afetam as periferias urbanas, convertendo-as nos territórios que expressam com maior evidência a rapidez e características de dita transformação. 
Este artigo se organiza a partir de estabelecer as possibilidades da literatura como insumo complementário para o estudo da história da cidade. Em um primeiro momento identificam-se as periferias metropolitanas em seu carácter paisagístico e dinâmico como amostra da mudança urbana, o que se complementa com a pertinência dos estudos da geografia histórica. Finalmente utiliza-se o livro El Alférez Real de José Eustaquio Palacios que narra as paisagens e trajetos entre a fazenda Cañasgordas e a cidade de Cali em 1789, descrevendo ao assentamento urbano e a extensa distância para então (10 quilômetros) de áreas rurais que a separava da fazenda e era recorrida a cavalo.

\section{Introducción}

Este artículo se apoya en la literatura costumbrista e histórica para reflexionar sobre la expansión urbana de Cali, se utiliza como referencia y preocupación la suerte de un patrimonio arquitectónico de la ciudad como es la hacienda Cañasgordas, descrita en el libro El Alférez Real de José Eustaquio Palacios (1886), que narra los paisajes y trayectos entre la hacienda y la ciudad de Cali, alrededor del año de 1789.

La hacienda Cañasgordas, construida como residencia del Alférez Real en el siglo XVIII - al sur de la ciudad de Cali en el camino a la ciudad de Popayán (ciudad capital de la provincia de la cual Cali dependía)-, es un legado del periodo donde la hacienda era el artefacto arquitectónico, al tiempo que la estructura social y de la propiedad rural, centro de las actividades económicas más importante en el valle del río Cauca. La tipología de la casa de hacienda, por su naturaleza funcional, alejada originalmente del casco urbano, servirá de hito para referenciar el carácter de la expansión urbana de carácter metropolitano y observar como esta "vorágine urbana", difusa y acelerada, absorbe, sin consideraciones, la estructura ecológica y el patrimonio histórico construido.

Se realiza una mirada histórico-hermenéutica de la configuración del paisaje metropolitano de la ciudad de Cali y su área de influencia, en el sur del departamento del Valle del Cauca y norte del departamento del Cauca, a manera de una arqueología del paisaje en términos de lo planteado por los geógrafos Sauer (1940) y De Bolos (1992).

El ejercicio que se propone se nutre, fundamentalmente, de los aportes, que desde los años setenta del siglo XX, planteó la Geografía Radical, que desnaturaliza el espacio al asumir que el espacio geográfico no es un ente natural sino un subproducto social del modo de producción, y que su comprensión solo es posible a partir de una geohistoria que implica el conocimiento de los procesos involucrados en su producción. La perspectiva de la producción del espacio (Harvey 1985, 1989, 1996, 2000; Soja, 1989, 1996, 2000; Santos, 1992, 2000) está en el centro de la reflexión que se pretende realizar. El paisaje es el producto de la estructura social en juego con los agentes e instituciones sobre el espacio físico.

Se pretende, metodológicamente, echar mano de la literatura en un ejercicio drid, España). Actualmente es Doctorando en estudios territoriales (Universidad de Caldas, Manizales). Es profesor nombrado del Departamento de Geografía de la Universidad del Valle, Cali. Hace parte del grupo de investigación Territorios, indexado en Colciencias. Área de estudio: geografía urbana, ordenamiento territorial, producción del espacio metropolitano. Correo electrónico: pedro. martinez@correounivalle. edu.co 
hermenéutico-histórico, como fuente rica en memorias del territorio, con la cual se puede realizar un análisis diacrónico del proceso de configuración territorial, en donde las periferias evolucionan en tiempo y espacio. Se tomará una novela que se desarrolla en la ciudad de Cali, El Alférez Real, novela costumbrista escrita en 1886 por el vallecaucano Eustaquio Palacios con narraciones sobre cómo era la vida a finales del siglo XVIII, en los últimos años de la Colonia y de la sociedad inmediatamente anterior a la Independencia en la ciudad de Cali, que permitirá localizar y contrastar el desarrollo urbano de la Cali del Siglo XVIII con el de estos días.

\section{El paisaje urbano: dinámicas y permanencias}

Es el paisaje - los paisajes - el resumen atravesado de configuraciones espaciales, producto de la interacción de agentes, estructura social e instituciones, realizadas dinámicamente en el tiempo donde pueden mirarse las periferias urbanas en distintos momentos. Allí la literatura se ofrece como una fuente útil para acercar a la comprensión de dichas configuraciones (espacio y tiempo). Las periferias - con su capacidad de ser paisajes y espacios de transición dinámicos- son hechos nuevos y en construcción frente a la ciudad consolidada, que responden a las características políticas, económicas, sociales, tecnológicas y culturales de cada sociedad en cada momento histórico y que sufren - en ciudades metropolitanas - procesos de consolidación, absorción y de relevo hacia sucesivas nuevas periferias de nuevo tipo. En dicho proceso espacial-temporal dinámico se juega la configuración del territorio.

La ciudad de Cali creció, poco y lentamente, en espacio y tiempo manteniendo una estructura heredada de la colonia del tipo centro-periferia, con una periferia rural estable desde su fundación (1536) hasta la llegada del siglo Xx. La ciudad pasa de ser un casco urbano compacto - que gira social, cultural, política y económicamente alrededor de la plaza mayor, con un perímetro urbano claramente contrastado entre el "adentro" y el "afuera" de la ciudad- a una ciudad fragmentada, con una periferia dispersa más extensa que todo el desarrollo urbano consolidado desde su fundación hasta los años ochenta del siglo xx. Tal transformación fue operada a la luz de los cambios en aspectos económicos (mercantilismo en auge), tecnológicos (vía al mar, tranvía, ferrocarril en las dos primeras décadas del siglo xx) y políticos (separación del departamento del Cauca y creación del departamento del Valle, con Cali, erigida como su capital en 1910) que se suscitaron en el siglo Xx, lo que propició que se convirtiera, aceleradamente, en la metrópoli que hoy conforma un espacio conurbado complejo que impacta territorios de municipios vecinos y sobre la cual gravita funcionalmente la vasta región del suroccidente colombiano.

Los objetos físicos aseguran la continuidad del tiempo, la memoria. Pero lo hacen por medio de la sucesión de los acontecimientos, que cambian su sentido, en re- 
lación con los sujetos que significan. El objeto tiene autonomía de existencia, debido a su existencia corpórea, pero no tiene autonomía de significación. Según Whitehead (1919) "el cambio en un objeto viene de las diferentes relaciones que mantiene con los diversos acontecimientos" (p. 63). Santos Milton (2000) agregaría la relación con la sociedad que hereda, reconstruye o innova dichos objetos desde sus posibilidades. Por tanto, el espacio construido testimonia la realización de la historia, siendo, al mismo tiempo, pasado, presente y futuro.

En el sentido de lo planteado por Santos Milton (2000), los lugares son expresiones presentes de dinámicas pasadas y de expectativas frente al futuro, le cabe a las periferias urbanas - siendo lugares privilegiados de tales dinámicas de transformación- una arqueología de las sucesivas periferias, que permita develar las configuraciones territoriales y las territorialidades de cada época, con sus factores causales y sus impactos territoriales en el paisaje y en la sociedad. La geografía histórica reconoce la necesidad de vincular transformaciones espaciales con hechos y actores situados históricamente. Así, los cambios de tiempo, distancia, conectividad o funcionalidad de las relaciones centro-periferia caracterizan relaciones de poder y de agentes en la producción del territorio (figura 1).

\section{Hacia una geografía histórica}

Cada paisaje humano, cada habitación son siempre una acumulación de experiencia práctica. El geógrafo no puede estudiar
Figura 1. Iglesia La Merced

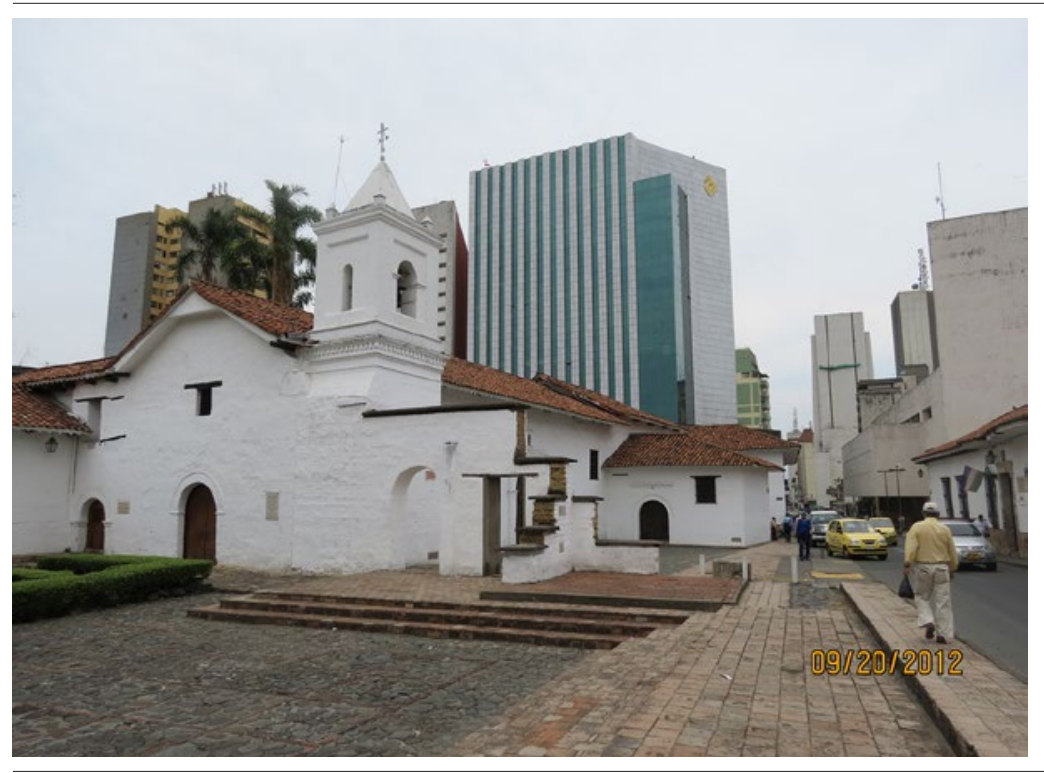

Nota: Arquitectura de la Colonia contrastada con la arquitectura reciente en el centro de Cali. Fuente: elaboración propia (2012).

casas y pueblos, campos y fábricas, en lo que respecta a su ubicación y su razón de ser, sin preguntarse por sus orígenes. Como planteó Sauer (1940), el geógrafo no puede tratar la localización de actividades sin conocer el funcionamiento de la cultura, los procesos de vida en comunidad del grupo, y solo puede hacer esto mediante la reconstrucción histórica. Si el objetivo consiste en definir y entender las asociaciones humanas como crecimientos en áreas, se debe descubrir cómo han llegado a ser lo que son en sus distribuciones (asentamientos) y actividades (uso de la tierra).

El estudio de áreas culturales es geografía histórica. La calidad de la comprensión que se busca depende del análisis de territarias 33 
orígenes y procesos, y el objetivo general es la diferenciación espacial de la cultura. $\mathrm{Al}$ ocuparse del hombre, y al ser analizado en una perspectiva genética, el tema se vincula necesariamente con secuencias en el tiempo. Lo retrospectivo y lo prospectivo son fines diferentes de la misma secuencia, donde el presente, por tanto, no es más que un punto en una línea, cuyo desarrollo puede ser reconstruido desde sus inicios, y cuya proyección puede ser llevada hacia el futuro.

El geógrafo histórico, por tanto, debe ser un especialista, porque no puede limitarse a conocer el territorio y el paisaje en su apariencia actual, sino que debe conocer sus rasgos fundamentales, tan bien como sea necesario, para encontrar en ellos trazas del pasado, y debe conocer sus cualidades con el detalle necesario para verla como era en situaciones del pasado. Podría decirse que necesita la capacidad de ver la tierra con los ojos de sus antiguos ocupantes, desde el punto de vista de sus capacidades y sus necesidades. Hay herramientas variadas para aproximarse al estudio histórico de la ciudad y sus transformaciones, en esta ponencia se identificará la posibilidad —en circunstancias de ausencia de precariedad de información histórica- de la literatura narrativa y descriptiva como un insumo sumamente útil.

\section{La literatura como fuente de información para el estudio del territorio y del paisaje}

\section{territorias 33}

De acuerdo con De Bolos (1992), para conocer la evolución del paisaje se deben tener una finalidad y escala definidas: "debemos plantearnos si el trabajo es un análisis de un momento pasado concreto, si su finalidad es comprender el presente o si tiene planteamientos más ambiciosos para el futuro". Las escalas de trabajo hacen alusión al tamaño de espacio a estudiar y los periodos a considerar. Hacerse una idea de la dinámica del paisaje en un periodo largo será posible únicamente por medio de imágenes fijas de momentos y espacios concretos.

En cuanto a la finalidad de la arqueología del paisaje, se puede pensar en una metodología que permita, por un lado, conocer posibles escenarios tendenciales del territorio, pero, por otro, mediante él se descubre, precisamente, su proceso de construcción por el que la sociedad se ha arraigado a un espacio y le ha dado una personalidad única, constituida por símbolos, hitos, leyendas, costumbres.

De Bolos (1992) propone, como segunda fase del estudio del paisaje, decidir si se hace un estudio de regresión histórica, es decir, partir de la imagen del presente hasta llegar a una del pasado, o, si se desea, partir de una imagen del pasado para llegar al presente, método que se llama progresión histórica. Sea cual fuere el método, implica la determinación de cortes diacrónicos: momentos en el tiempo que serán analizados. Cuanto más contiguos sean, más cerca se estará del conocimiento de la evolución del paisaje, todo depende de la información con que se cuente. Una vez realizado este punto, también es necesario determinar las fases históricas que son marcadas por even- 
tos importantes. Un evento importante es un conjunto de acciones muy cercanas en el tiempo que cambiaron fuertemente la estructura del paisaje; se puede decir que, entre eventos, el paisaje estuvo relativamente estable.

De Bolos (1992) agrupa los documentos escritos, como fuente de información, en conjuntos de documentación dispersa, entre los que se encuentran crónicas medievales, cartas de población, documentación notarial, archivos eclesiásticos, cartulanos medievales, pergaminos y documentos particulares; los libros de viajes y, por último, el catastro. La autora también manifiesta que el uso de estos documentos presenta problemas en la reconstrucción de un momento de la historia del paisaje: imprecisiones geográficas y de localización, imprecisiones terminológicas, imprecisiones cronológicas, datos referidos a espacios pequeños, y no a regiones o paisajes, y, por último, la toponimia que cambia con el tiempo pero también que se repite en el espacio.

Desde luego, la literatura (desde las crónicas, hasta la novela costumbrista, histórica, biográfica, regionalista, etc.), por su propia esencia, debe considerarse como una fuente de información escrita a ser tenida en cuenta en la arqueología del paisaje, ya que en ella el autor ha plasmado características propias del escenario - el contextomientras se narra la historia de los personajes centrales de su obra. Esta fuente de información también presentará la misma problemática que las demás propuestas por De Bolos (1992).
Precisando en la forma en la que la literatura se puede utilizar como fuente de información en los estudios del territorio y el paisaje, Carreras (1998) propone tres fases metodológicas: (a) La lectura desprevenida pero apasionada de la obra, (b) $\mathrm{La}$ recolección de datos y (c) El análisis a partir de los datos extraídos de la obra.

Carreras dice que los datos extraídos de la obra se pueden sistematizar en dos tipos, por un lado, en notas que pueden ser catalogadas por categoría de espacios (regiones, ciudades, lugares), tipos de personajes, cronológica o temáticamente; $y$, por otro, en mapas clasificados por temas. Esta sistematización permite la posterior interrelación de eventos con lugares específicos, lo que facilita el encuentro en la obra de aquellos apartes que deben ser tenidos en cuenta a la hora de concretar los objetivos de estudio.

La cartografía del territorio de la obra permite hacer una segunda escritura de esta, es hecha por el geógrafo, quien, a partir de la narrativa, reconstruye la localización de los lugares y regiones, las trayectorias de los itinerarios y la caracterización de los entornos, representándolos en zonificaciones de uso, ocupación y atributos biofísicos.

La cartografía o los referentes territoriales espacializables de la obra literaria pueden ser contrastados y complementados con la cartografía histórica de la época, que se guarda en los diferentes archivos y bibliotecas, esto con el fin de complementar y comprender el contexto espacial y territorial. Es a partir de esta información 
sistematizada que el investigador del territorio inicia el análisis.

\section{El Alférez Real y la periferia colonial de Cali (1789)}

El Alférez Real, escrito en 1886 por el autor colombiano José Eustaquio Palacios (1830-1898), es una crónica de Cali en el siglo XVIII y se le considera obra cumbre de la novela histórica granadina. Palacios escribió esta novela, más con la intención de presentar una ciudad y una época que con la de narrar una historia. La trama, bastante sencilla, se basa en la imposibilidad del amor por causa de la desigualdad social. La novela tiene excelentes narraciones sobre cómo era la vida a finales del siglo XVIII, ayuda a comprender los últimos años de la Colonia y a la sociedad inmediatamente anterior a la Independencia.

Es importante señalar que José Eustaquio palacios consultó los archivos históricos, en particular en los archivos del Cabildo, de la Notaría y de la Parroquia de Cali. Sus descubrimientos más sus propios recuerdos de su temprana vida entre los franciscanos son el insumo para que él escriba y narre, por ejemplo, la jura de fidelidad al rey de España, las sesiones del Cabildo, las actuaciones del Alférez Real de la ciudad - don Manuel Caicedo Tenorio-y muchos aspectos de la vida social de la Cali colonial (Silva, 1972).

El de Alférez Real era un cargo honorífico durante la Colonia de la Corona Española, era un integrante del cabildo indiano, cargo puramente ceremonial, cuya única función consistía en pasear el estandarte real en celebraciones y en ceremonias oficiales, representando al Rey de España. Sin tener un poder administrativo o político real, era una figura respetada a la que la Corona le otorgaba algunos privilegios, entre ellos, el de asignar a su familia importantes terrenos.

Si bien, se reconoce que el autor realizó estas investigaciones, es importante enfatizar en que se trata de un texto de ficción que comparte las convenciones de la novela romántica del siglo XIX y que, además, fue escrita muchos años después de lo que se narra.

\section{Cali, la ciudad colonial en 1789}

Respecto de la extensión de la ciudad de Cali, la forma de sus calles, las actividades de la población, la localización de sus hitos urbanos, las relaciones topológicas entre la ciudad de Cali y la hacienda, así como las descripciones de la vida cotidiana de sus habitantes y de las periferias o "inmediaciones de la ciudad" Palacios (1940 [1886]) es pertinente y elocuente:

A principios del mes de Marzo de 1789, un sábado como a las cinco y media de la tarde, tres jinetes bien montados salían de Cali, por el lado del Sur, en dirección a la hacienda de Cañasgordas.

[...] Las afueras de la ciudad ofrecían por ese lado y a esa hora bastante animación. Varios vecinos volvían de su trabajo con la herramienta al hombro; bestias cargadas de plátanos o leña; mujeres con haces de leña

Pedro Martín Martínez Toro 
en la cabeza; viajeros que llegaban de los pueblos del Sur; arrieros con sus recuas cargadas de bayeta, papas o anís; algún negro joven que pasaba a escape en su caballo en pelo y que iba a la ciudad tal vez a comprar lo que faltaba para la cena en alguna hacienda o granja vecina; los criados de la hacienda de Isabel Pérez que apartaban las vacas de los terneros como es costumbre a esa hora; y todo esto acompañado del mugir de las vacas, del berrear de los terneros, de los gritos de los criados, de las interjecciones de los arrieros y de esos otros mil ruidos que se oyen en las casas de campo y en las inmediaciones de una ciudad cuando va entrando la noche.

Sobre todo son útiles para la contextualización geográfica e histórica las descripciones sobre el tamaño, perímetros y población de la ciudad, apegado a los datos censales de la época. Aspectos que permiten caracterizar en un momento histórico a la ciudad y dimensionar los cambios que se pueden constatar en la actualidad:

[...] Cali no tenía en aquel tiempo la misma extensión que tiene ahora ni menos el número de vecinos que cuenta actualmente. Según el riguroso empadronamiento hecho en 1793. El recinto de la ciudad sólo contenía seis mil quinientos cuarenta y ocho habitantes; y de éstos, mil ciento seis eran esclavos.

[...] En ese año, pues, de 1789, la ciudad se extendía desde el pie de la colina de San Antonio hasta la capilla de San Nicolás, y desde la orilla del río, hasta la plazuela de Santa Rosa. Ese extenso barrio que existe hoy desde la plazuela hasta el llano, es enteramen- te moderno. Aunque el área de la población era grande, los edificios no eran tantos como podían caber en ella; porque había manzanas con sólo dos o tres casas, cada casa con un espacioso solar, y cada solar sembrado de árboles frutales, principalmente cacao y plátano y algunas palmas de coco. Los árboles frutales eran los mismos que hay ahora, con excepción del mango que no era conocido todavía $(1940$, p. 3$)$.

\section{La ciudad como paisaje con una periferia compacta}

La novela de Palacios (1940 [1886]) permite comprender el carácter compacto y de lenta dinámica en su crecimiento, al tiempo que el contraste entre la concentración urbana y la dispersión y bajas densidades del suelo rural apocas cuadras de la plaza mayor:

[...] El río [Cali] no tenía puente permanente. Cada año se hacía uno de madera y guadua un poco más abajo de la Ermita, que las crecidas, al entrar las lluvias, se llevaban por delante, dejando cuando más los horcones (1940, p. 58).

En el otro lado del río había solamente tres o cuatro casas en forma de quintas o pequeñas haciendas algunas con plantaciones de caña y trapiche. El resto de todo ese terreno estaba cubierto de guayabales, que comenzando en el Charco de la Estaca iban a terminar en Menga (1940, p. 59).

Destaca a la arquitectura religiosa, sobresaliente aún en una ciudad periférica y 
pobre (el poder político, religioso y económico se centraba en las ciudades de Santafé de Bogotá y de Popayán) de la Colonia española en América, marcando su escasa extensión y su perfil compacto:

[...] Estando la ciudad tan ventajosamente situada, el viajero que se dirigía a ella, la alcanzaba a ver desde dos o tres leguas de distancia, cubierta de árboles; sobre los árboles se destacaban las palmas en un gran número y en toda su gentileza; y por entre las palmas se distinguían los blancos campanarios de sus iglesias. Cualquiera hubiera creído tener a la vista una ciudad oriental, tal vez Bagdad, coronada de palmeras y minaretes (1940, p. 64).

Evidencia el emplazamiento de la ciudad de Cali sobre el piedemonte de la cordillera occidental (1000 ms.n.m.), aspecto que relativamente cambió al extenderse la ciudad hacia el oriente, ocupando suelos inundables por el río Cauca:

[...] Al Norte el horizonte es tan extenso y el Valle por ese lado es tan bajo, que, como en el mar, se alcanza a ver el cielo sin alzar los ojos. A dos leguas de distancia (1 legua son $4,83 \mathrm{~km}$ ) se levanta la ciudad de Cali, reclinada sobre las faldas de la cordillera, coronada de montes y collados, de campanarios y de palmas, arrullada por el murmurio de su río, a la sombra de sus naranjos, nísperos y tamarindos; refrescada por las brisas de la sierra y perfumada por el aroma de los azahares, flor aristocrática, de blancura sin mancilla, emblema de la pureza, escogida por las vírgenes para tejer con ella sus coronas (1940, p. 128).

\section{La hacienda de Cañasgordas del paisaje rural colonial a la periferia urbana dispersa y difusa contemporánea}

La Hacienda Cañasgordas es una hacienda ubicada en el sur de Santiago de Cali, Colombia. Antes conocida como la Casa Grande, la construcción de la casona data del siglo XVIII y es un legado del periodo donde la hacienda era la actividad económica más importante del Valle del Cauca (Santiago, 1965). José Eustaquio Palacios describe —en El Alférez Real- límites y extensión - constatables con instrumentos notariales - de la hacienda "Cañasgordas" que dan muestra del tamaño del predio como de sus características geográficas:

[...] Cañasgordas era la hacienda más grande, más rica y más productiva de todas cuantas había en todo el Valle, a la banda izquierda del río Cauca.

Su territorio era el comprendido entre la ceja de la cordillera occidental de los Andes y el río Cauca, y entre la quebrada de Lili y el río Jamundí.

La extensión de ese territorio era poco más de una legua (1 legua son 4,83 km) de Norte a Sur, y varias leguas de Oriente a Poniente (1940, p. 14).

La hacienda se localizaba en las afueras de la ciudad de Cali, distante de su centro urbano unos diez kilómetros, dato útil como referencia de la evolución del crecimiento urbano de la ciudad (figuras 2 y 3 ). 
Figura 2. La ciudad y la hacienda en el camino a Popayán (capital de la provincia del Cauca)

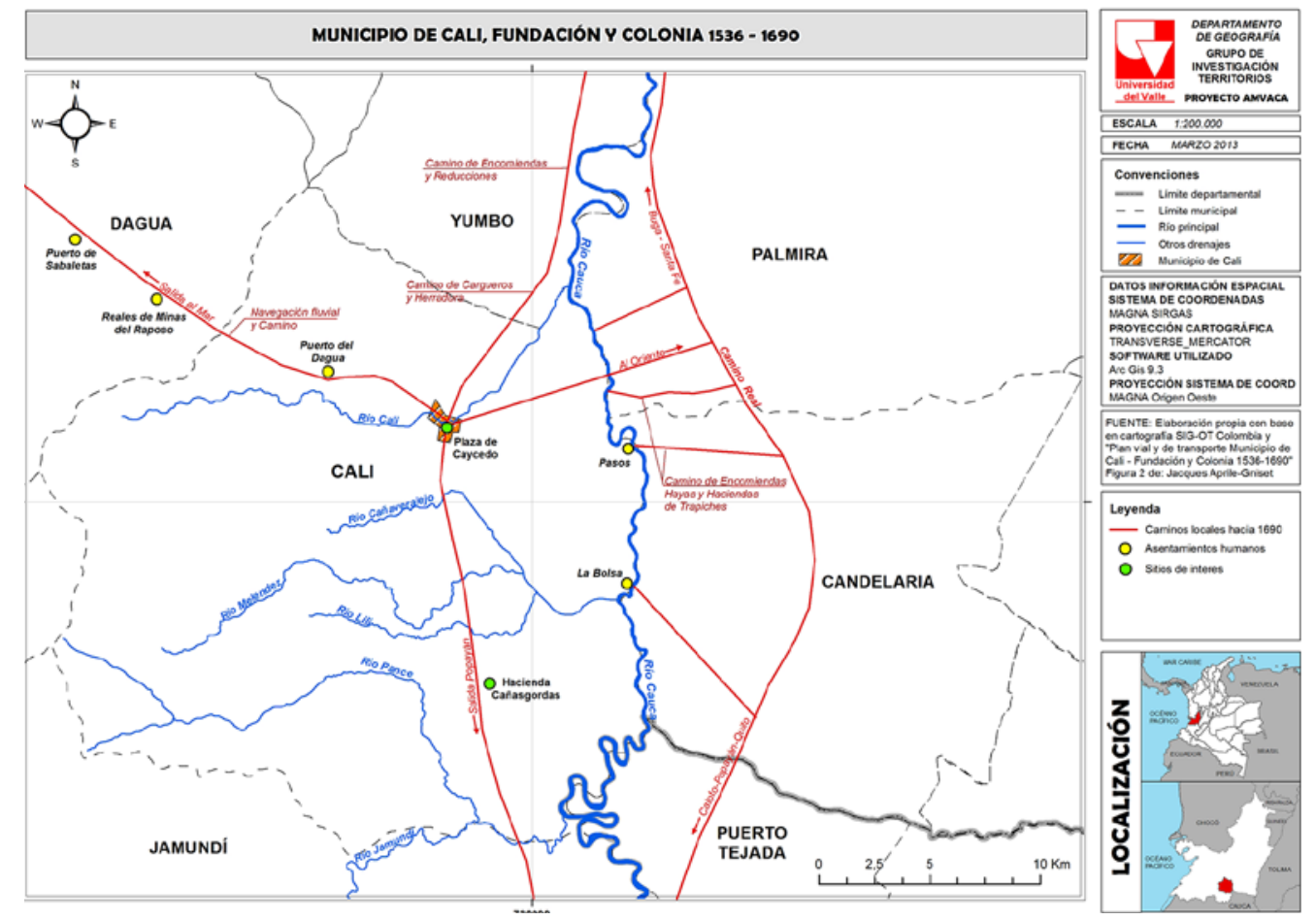

Fuente: Martínez \& Patiño (2015).

Figura 3. Hacienda Cañasgordas (arquitectura de la Colonia)

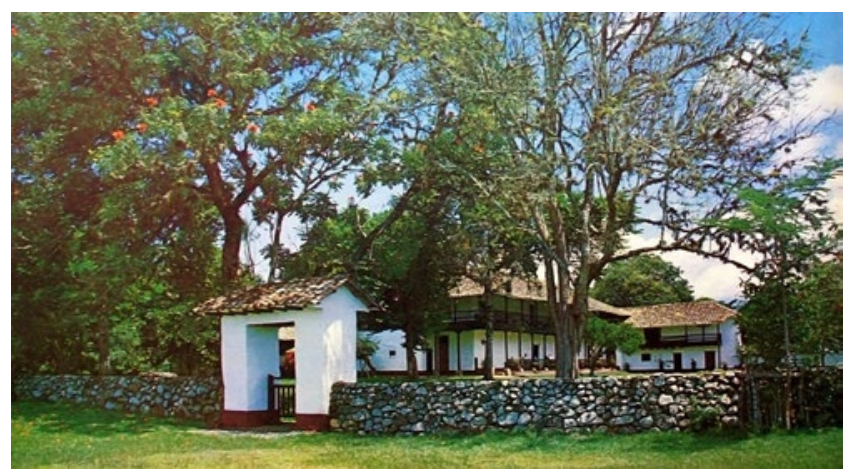

Nota: hoy deteriorada en sus acabados y estructura.

Fuente: elaboración propia (2012). 
El contexto geográfico de la hacienda referido a hechos naturales como la hidrografía y la topografía se exponen de tal manera que establecen las relaciones topológicas, paisajísticas y ecológicas:

[...] Descendiendo por la colina, se ven a la derecha vastas praderas regadas por el cristalino Pance, que tienen por límite el verde muro de follaje que les opone el Jamundí con sus densos guaduales; a la izquierda, graciosas colinas cubiertas de pasto, por entre las cuales murmura el Lili, casi oculto a la sombra de los carboneros; y allá abajo, en donde desaparece la gran colina, se extiende una dilatada llanura cubierta de verde césped, que va a terminar en las selvas del Cauca, y que ostenta, colocados a regulares distancias, árboles frondosos, o espesos bosquecillos, dejados allí intencionalmente para que a su sombra se recojan a sestear los ganados en las horas calurosas del día (1940, pp. 14-15).

En ese vasto y hermoso territorio se expande - presionado por la ambición de los agentes del mercado inmobiliario y por el laissez faire del Estado, incapaz de planificar en favor de la preservación de los ecosistemas estratégicos o del patrimonio histórico- desde hace unas tres décadas (desde comienzo de los años ochenta del siglo Xx) la "ciudad sin confines" (Nel-lo, 1998), la "Privatopia" (Garreau, 1991; McKenzie, 1994), la "ciudad difusa” (Indovina, 1990), en fin, eufemismos para intentar describir la ciudad dispersa sin espacio público de calidad, la que teme a los peatones y, por tanto, crece sin andenes ni parques, la que esconde sus fachadas detrás de mallas cada vez más altas, electrificadas y con cámaras de seguridad sumadas a densos muros de setos. Al decir de Sainz (2006):

Todos - los eufemismos - ellos pretenden referirse a ese conjunto de estructuras físicas que ocupan territorios cada vez más amplios cuyo orden no se llega a percibir recurriendo a las lógicas de formación de la ciudad compacta tradicional y que sin embargo constituyen eso que se podría denominar con toda propiedad la "ciudad contemporánea"; si es que el término "ciudad" puede seguir sirviendo para dar razón de lo urbano hoy, pues una parte del problema actual se encuentra en la falta de términos precisos, que acaba provocando su empleo en sentido analógico o figurado, cuando no puramente metafórico (p. 209).

\section{Las periferias de la ciudad metropolitana en mutación permanente}

La complejidad de la voz y el sentido de la palabra periferia han llevado a esfuerzos por producir neologismos interpretativos de la realidad del crecimiento metropolitano en contextos de globalización como los de "megalopolis" (Gottman, 1961), “exopolis” (Soja, 1996), “metápolis” (Ascher, 1995), "archipielago urbano" (Veltz 1999).

\section{Según Hiernaux y Lindon (2004):}

La voz periferia lleva consigo sedimentos de sentido de la voz arrabal: lo malo, los bajos

Pedro Martín Martínez Toro 
fondos, la falta de moral, el territorio poblado por sujetos peligrosos. Pero también lleva sedimentos de la voz suburbio: la ilusión de la vida tranquila y natural (p. 119).

Nada como la ciudad para ser dinámica, al punto de poder contener en gran medida toda la historia de la humanidad y de la periferia para expresar permanencias y cambios; conflictos, traslapes de formas y funciones: paisajes en permanente construcción. De allí que las periferias sean susceptibles de ser estudiadas en su evolución en el tiempo, su evolución permanente en sistemáticas fronteras sucesivas. La versión contemporánea de esta periferia de Cali son los conjuntos residenciales cerrados en tipología de apartamentos y casas a manera de ciudadelas aisladas (figura 4).

Figura 4. Periferia reciente de Cali alrededor de la hacienda Cañasgordas

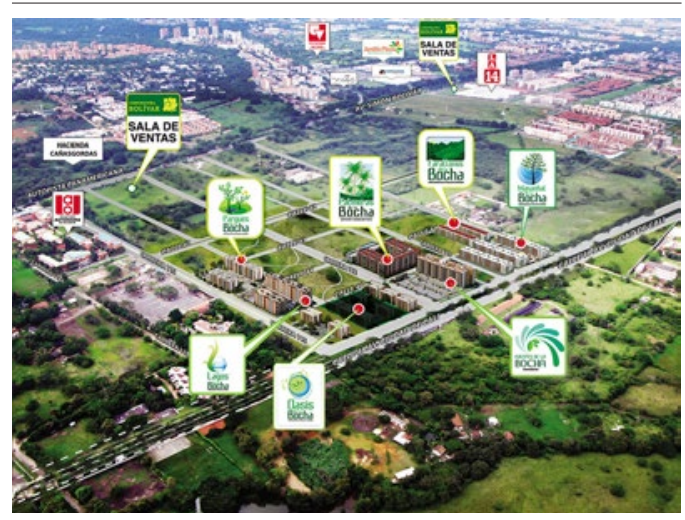

Fuente: Constructora Bolívar. Disponible en http://www. constructorabolivar.com

Con una evidente falta de originalidad, al tiempo que se oculta la esencia del patrimonio histórico, se toma solo el nombre del patrimonio como toponímico. El nombre de la hacienda Cañasgordas sirve ahora para nombrar fragmentos homogéneos de condominios residenciales que construyen la Cali contemporánea, por medio del modelo del conjunto residencial cerrado. Los nombres de los recientes proyectos residenciales son, entre otros, Condominio Hacienda del Alférez; Portal del Alférez; Casas del Alférez I, II, III y IV; Torres del Alférez I; (Constructora Meléndez) (figura 5). Situación que, a una escala del sector - la suma de todos los conjuntos residenciales cerrados - evidencia la forma del crecimiento urbano de la ciudad de Cali de manera - dispersa, difusa y fragmentada (figuras 10 y 11 ).

Figura 5. Condominio "Casas del Alférez IV" de la Constructora Meléndez

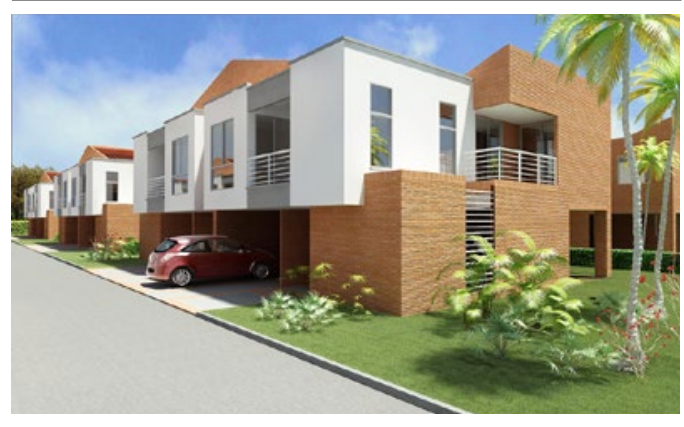

Fuente: Constructora Bolívar. Disponible en http://www. constructorabolivar.com.

Un recorrido por el entorno de la $\mathrm{Ha}$ cienda Cañasgordas y por los lugares que describe la novela de Palacios (1886) permite observar la manera en la que la expansión urbana contemporánea transforma territarias 33 
${ }^{1}$ http://www.jaramillomora.com/llanosdepance. html\#sthash.llS8F4NO.dpuf

aceleradamente las calidades del territorio narrado en la novela (figuras 6, 7 y 8 ).

Figura 6. Proyectos residenciales en vecindades del río Pance

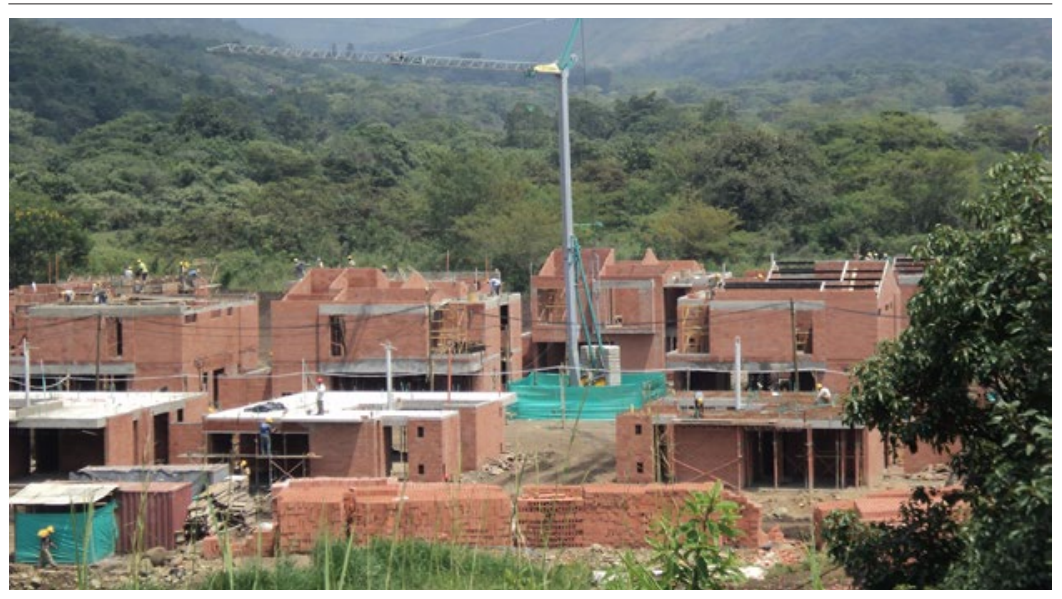

Nota: Llanos de Pance, Constructora Jaramillo Mora.

Fuente: elaboración propia (2012).

Figura 7. Proyectos residenciales en vecindades del río Pance

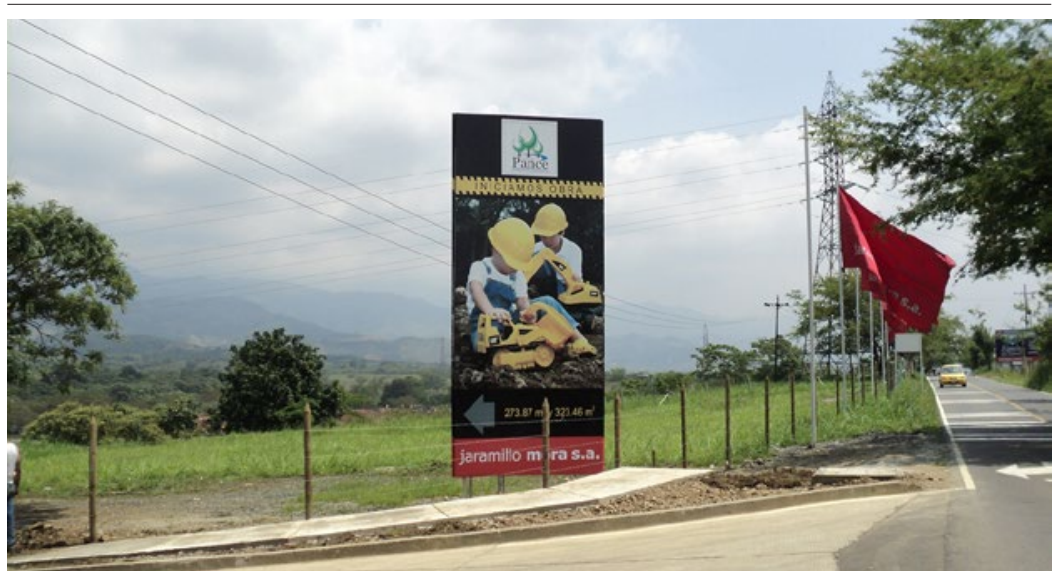

Nota: Llanos de Pance, Constructora Jaramillo Mora.

Fuente: elaboración propia (2012).

territarios 33 $\begin{array}{r}\text { Como ejemplo, se puede ver cómo la } \\ \text { Constructora Jaramillo Mora (2015), en su }\end{array}$ 76 página web, en el apartado de "proyectos ejecutados" describe el proyecto Llanos de Pance, localizado a orillas del río Pance (Calle 4 \# 118-50, Pance, Cali), como un proyecto en el nuevo sector de expansión urbana para los más altos estratos socioeconómicos de la ciudad, denominada por ellos como "sector Pance Alto" así:

Se encuentra ubicado en el exclusivo sector de Pance Alto, privilegiado por ser uno de los últimos lotes urbanos en ese sector, sus espectaculares visuales hacia los Farallones, con una acequia que lo atraviesa, creando un ambiente lleno de tranquilidad, libre de contaminación y propicio para la contemplación de diferentes especies de la fauna local, amplias zonas comunes, vías de acceso y plan vial. Cerca de prestigiosas universidades, colegios y a pocos minutos de importantes centros comerciales y almacenes de cadena, como Carulla, Jardín Plaza y Unicentro. ${ }^{1}$

Llanos de Pance, junto a otros dos condominios campestres, Alto Pance y Reserva Pance, desarrollados por la misma constructora, evidencian el interés por urbanizar esta última cuenca hidrográfica que le queda a la ciudad con calidades ambientales para la recreación. De hecho, es considerado el último sitio de esparcimiento y recreación pública de la sociedad caleña amante de la naturaleza que sale a caminar o trotar y, sobre todo, para los de escasos recursos económicos que no tienen para pagarse unidades residenciales con piscina y acuden al río los fines de semana multitudinariamente para bañarse en sus cristalinas 
y frescas aguas - un oasis en la calurosa Cali- . Un destino como el que ya vivieron las cuencas de los ríos Cali, Cañaveralejo, Meléndez y Lilí, hoy convertidas en cloacas urbanas, sería el futuro de las "vastas praderas regadas por el cristalino Pance" (Palacios, 1940, pp. 14-15) (figuras 8 y 9).

La imagen de la hacienda Cañasgordas - muy débil o inexistente en el imaginario colectivo - se muestra totalmente absorbida por el crecimiento reciente de la ciudad en los últimos quince años (después de 1998) (figuras 10 y 11). Es un proceso que no se detiene, alimentado por la voracidad del capital transnacional del sector inmobiliario, borrando a su paso el patrimonio natural (ríos, fauna y flora) y el patrimonio construido como la hacienda Cañasgordas.

En la figura 11 puede observarse cómo la hacienda Cañasgordas, ya desde el año 1998, es alcanzada por la expansión al sur de la ciudad de Cali y, ya en 2007, se encontraba subsumida en la punta de lanza de la conurbación metropolitana de las ciudades de Cali y Jamundí.

\section{Conclusiones}

El territorio, esa construcción humana en la que somos herramienta y producto, tiene una expresión fisonómica llamada "paisaje", esa imagen representa un momento de la historia del territorio; sin embargo, este es dinámico. Conocer la evolución del paisaje implica mirar las transformaciones del territorio en el tiempo, y los estudios territoriales interesados en la búsqueda de las explicaciones de la configuración del
Figura 8. Tres proyectos recientes de la Constructora Jaramillo Mora

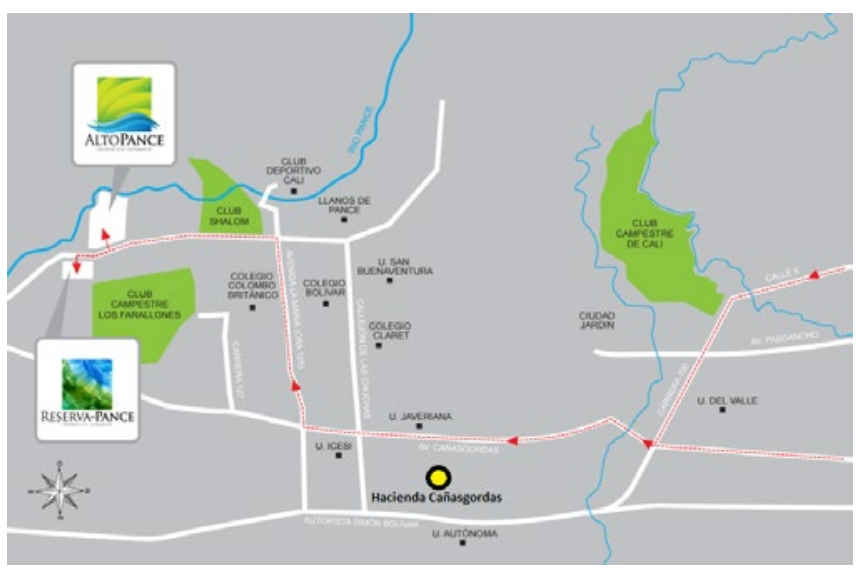

Nota: Llanos de Pance, Altos de Pance y Reserva Pance, Condominios Campestres. La urbanización avanza sobre la cuenca del río Pance.

Fuente: Constructora Jaramillo Mora Disponible en http://www.jaramillomora.com/ reservadepance.html

Figura 9. Balnearios y centros recreativos privados y públicos ocupan ilegalmente parte del cauce del río Pance

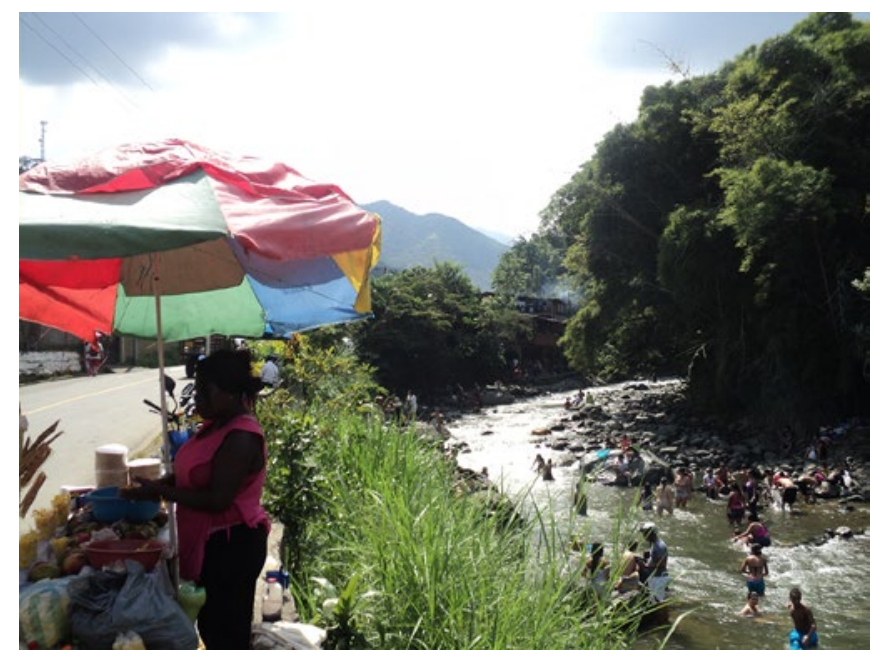

Fuente: elaboración propia (2014).

territarias 33

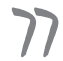


Figura 10. Periferia urbana sur de la ciudad de Cali



Nota: imagen realizada sobre el antiguo camino a Popayán, hoy Autopista Cali - Jamundí.

Fuente: Google Earth (2012).

Figura 11. Distintos periodos del crecimiento de la "mancha urbana" de Cali

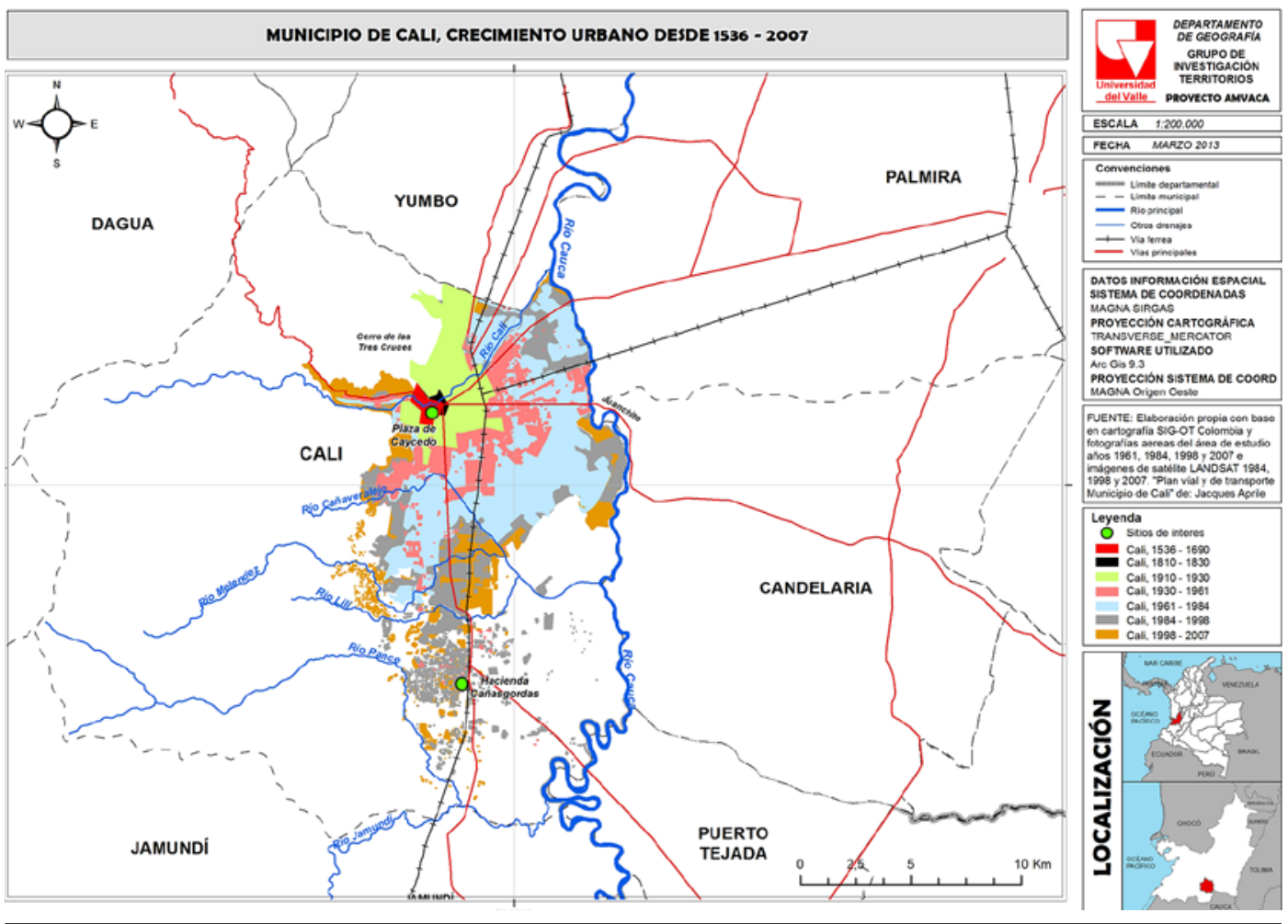

Fuente: Martínez \& Patiño (2015). 
territorio pueden proponer y asumir metodologías que se apoyen en la literatura.

La suma de muchas periferias en la historia de la ciudad, al final del día, es la ciudad como un palimpsesto que todavía conserva huellas de otra escritura anterior en la misma superficie, pero borrada o reconfigurada expresamente para dar lugar a la que ahora existe. Un hito sociohistórico (Hacienda Cañasgordas) que mediante el recurso de la literatura permite el análisis de la evolución de la periferia urbana (Cali).

La hacienda Cañasgordas al quedar - en este proceso de expansión urbanametafórica y literalmente absorbida por la ciudad y borrada formal y funcionalmente del mapa y de la imagen urbana de los habitantes, porque se cae a pedazos y porque el municipio permitió que se urbanizara todo su entorno mediante el exitoso modelo capitalista del conjunto residencial cerrado y la configuración del paisaje metropolitano disperso, difuso y fragmentado, que marca la urbanización contemporánea en contexto de globalización.

Un recurso interesante de análisis territorial, incluso de carácter pedagógico, es el poder realizar hoy el recorrido de ida y vuelta entre el espacio constreñido - que se cae a pedazos - de la casa de la hacienda Cañasgordas con sus alrededores en la zona del río Pance y el centro de la ciudad de Cali y poder constatar los cambios del paisaje y de los ecosistemas naturales y culturales. Ello serviría para reflexionar, más allá del edificio patrimonial, en el carácter de las periferias metropolitanas de hoy y en el papel del Estado frente a los agentes privados en la producción del territorio, y la posibilidad de cuestionarnos sobre las políticas públicas en materia de espacios protegidos y de protección y dar real cumplimiento del Artículo $10 .^{\circ}$ (Determinantes de los planes de ordenamiento territorial) de la Ley 388 de 1997 que regula la elaboración de los Planes de Ordenamiento Territorial $\mathrm{Mu}^{-}$ nicipal, especialmente numerales $1 .^{\circ}$ y $2 .^{\circ}$ (1. ${ }^{\circ}$ conservación y protección del medio ambiente, los recursos naturales y la prevención de amenazas y riesgos naturales y


sobre conservación, preservación y uso de las áreas e inmuebles consideradas como patrimonio cultural de la Nación y de los departamentos, incluyendo el histórico, artístico y arquitectónico).

\section{Referencias}

Ascher, F. (1995). Métapolis, ou l'avenir des villes. Paris: Odile Jacob.

Bolos, M. de (Dir.) (1992). Manual de Ciencia del Paisaje. Teoría, métodos y aplicación. Barcelona: Editorial Masson.

Carreras, C. (1998). El uso de los textos literarios en geografía. En A. García, Métodos y técnicas cualitativas en geografía social (pp. 163-176). Barcelona: Oikos Tau.

Garreau, J. (1991). Edge City: Life on the frontier. New York: Doubleday.

Gottman, J. (1961). Megalopolis (The Urbanized Northeastern Sea-board of the United States). Cambridge: MIT Press.

Harvey, D. (1985). The Limits to Capital. Oxford: Blackwell. territarias 33

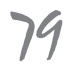


Harvey, D. (1989). The Condition of Postmodernity: an enquiry into the origins of cultural change. Oxford: Blackwell.

Harvey, D. (1996). ¿Cities or urbanization? City, Analysis of urban trends, culture, theory, policy action, 1-2, 38-61.

Harvey, D. (noviembre-diciembre, 2000). Reinventar la Geografía. New Left Review, N. ${ }^{\circ}$ 5, Madrid: Akal.

Hiernaux D., \& Lindon A. (2004) La periferia: voz y sentido en los estudios urbanos. Papeles de población, 10, 42, 101-123.

Indovina, F. (1990). La cittá diffusa. Venecia: Daest Ed.

Isaacs, J. (1969). María. Buenos Aires: Editorial Huemul.

Martínez, P., \& Patiño, Z. (2015). Área Metropolitana del Sur del Valle y Norte del Cauca (AMVACA); Diagnóstico, definición y propuesta de conformación. Cali: Programa Editorial Universidad del Valle.

McKenzie, E. (1994). Privatopia: Homeowner associations and the rise of residential private government. New Haven: Yale University Press.

Monclús, F. J. (1998) Suburbanización y nuevas periferias. Perspectivas geográfico-urbanísticas. En F. J. Monclús (Ed.) La ciudad dispersa (pp. 5-15). Barcelona: Centro de Cultura Contemporània de Barcelona.

Nel-lo, O. (1998). Los confines de la ciudad sin confines. Estructura urbana y límites administrativos de la ciudad difusa. En

\section{territarias 33}

(pp. 35-57). Barcelona: Centre de Cultura Contemporània de Barcelona.

Palacios, J. E. [1886 (1940)]. El alférez real. 6. ${ }^{a}$ Ed. Cali: Imprenta departamental del Valle.

Sainz V. (2006). El proyecto urbano en Espana; génesis y desarrollo de un urbanismo de los arquitectos. Sevilla: Universidad de Sevilla.

Santiago, S. (1965). Arquitectura Colonial en Popayán y el Valle del Cauca. Cali: Universidad del Valle.

Santos, M. (1992). 1992: A redescoberta da Natureza. Estudos Avançados, vol.6, n¹4, p. 95- 106.

Santos, M. (2000). La naturaleza del espacio. Barcelona: Ariel Geografía.

Sauer, C. O. (1940). Hacia una geografía histórica. Discurso a la Asociación Norteamericana de Geógrafos. Baton Rouge, Louisiana. Traducción de Guillermo Castro H. Recuperado de www. colorado.edu/geography

Silva, H. R. (1972). Eustaquio Palacios: de su vida y su obra. Cali: Editorial Feriva.

Soja, E. (1989). Post-modern geographies: the reassertion of space in critical social theory. Nueva York: Verso.

Soja, E. (1996). The third space: journeys to L.A. and other real-and-imaginated places. Oxford: Blackwell.

Soja, E. (2000). Postmetropolis. Critical Studies of Cities and Regions. Oxford: Blackwell Publishers.

Veltz, P. (1999). Mundialización, ciudades y territorios. La economía de archipiélago. Barcelona: Editorial Ariel Geografía. 
Whitehead A. N. (1919). An enquiry concerning the principles of natural knowledge. Cambridge: Cambridge University press. 